\title{
Messages from Parents of Children with Autism Spectrum Disorder (ASD)
}

\author{
Associate Professor Jill Bevan-Brown \\ Massey University
}

\begin{abstract}
This article presents the results of an on-line questionnaire answered by 137 parents of children with ASD. The questionnaire sought parental opinion about what content and messages should be included in a DVD about ASD. Parents' predominant messages were that: ASD is not an illness that can be cured; children with ASD think and act differently; people need to accept and accommodate these differences; include children with ASD and their families, and treat them with dignity and respect. Parents emphasised the importance of their children having friends, being included in everyday and special activities; being shown acceptance and kindness, and being safe in the school and community environment. They also described a variety of strategies that had proved successful with their children both at school and in the wider community. These strategies and parental concerns are strongly supported in the research literature.
\end{abstract}

\section{Research}

Keywords: ASD, Asperger syndrome, autism, parents, safety, teaching strategies

\section{INTRODUCTION}

In 2004 the author was commissioned by the New Zealand Ministry of Education to conduct a small research into Māori perspectives of ASD.

Māori parents who were interviewed in this study mentioned the frustration they felt in repeatedly having to explain their child's autism to others. One mother commented that it would be really helpful if there was a DVD explaining ASD, that she could share with family members, friends, community members, teachers and the child's peers. Responding to this need, the author and two parents from the original research approached the Ministry of Education to suggest that such a DVD be produced. Ministry personnel supported the idea and agreed to provide scoping money if the parents were willing to take on the task of producing the DVD. They were asked to submit a detailed proposal for consideration which was subsequently accepted. In order to receive the scoping grant, this small group was required to register as a charitable trust - hence the PAI 4 ASD Trust (Promotion of Acceptance and Inclusion 4 ASD) was formed.
After gaining approval from the Massey University Human Ethic's Committee, a questionnaire probing what parents of children with ASD thought should be included in a DVD was developed and posted on the Trust's website (www.inmyshoes. co.nz). Responses to this questionnaire informed the development of the "soft-script" for the DVD. Feedback on the script was sought from parents, students, community members, Māori and professional groups, and from siblings and children with ASD. Amendments were made and the final script was approved by various advisory groups representing teachers, principals, parents, professionals, community members, Māori, Autism NZ and the Ministry of Education. In addition to the scoping grant from the Ministry of Education, Trust members continued to seek funding, mainly from organisations such as Community Trusts and Public Charities. This money funded the initial production and has enabled 20,000 copies to be distributed free to every school in NZ, to a wide variety of medical, social and Māori organisations, and to individuals who have requested a copy via the Trust's website. The money was also used to commission the writing of resources for teachers, parents and family/whānau. These resources can be downloaded from www.inmyshoes.co.nz

\section{METHODOLOGY}

The on-line questionnaire contained ten questions:

\begin{tabular}{|l|l|}
\hline \multicolumn{2}{|l|}{ School Section } \\
\hline 1. & $\begin{array}{l}\text { What information or activities would help } \\
\text { teachers and peers to understand and } \\
\text { appreciate children and young people with } \\
\text { ASD in their schools? }\end{array}$ \\
\hline 2. & $\begin{array}{l}\text { Describe any experiences with your own } \\
\text { child that have contributed to him/her feeling } \\
\text { valued and accepted by school staff and/or } \\
\text { their peers. }\end{array}$ \\
\hline 3. & $\begin{array}{l}\text { What three key messages about your child } \\
\text { would you like school staff and peers to } \\
\text { know. }\end{array}$ \\
\hline Māori Section \\
\hline 4. & $\begin{array}{l}\text { Describe any Māori-specific situations that } \\
\text { have been particularly difficult for you and } \\
\text { your child with ASD. How have/could have } \\
\text { these situations been made easier? }\end{array}$ \\
\hline 5. & $\begin{array}{l}\text { In what ways would you like whanau } \\
\text { members to support you and your child? }\end{array}$ \\
\hline
\end{tabular}




\begin{tabular}{|l|l|}
\hline \multicolumn{2}{|l|}{ Community Section } \\
\hline 6. & $\begin{array}{l}\text { Describe any everyday situations that have } \\
\text { been particularly difficult for you and your } \\
\text { child with ASD (eg getting a hair cut, going } \\
\text { to the dentist, new neighbours etc) How } \\
\text { have/could have these situations been made } \\
\text { easier? }\end{array}$ \\
\hline 7. & $\begin{array}{l}\text { What strategies have you found helpful when } \\
\text { interacting with neighbours, community } \\
\text { members, service personnel, medical and } \\
\text { other professionals? }\end{array}$ \\
\hline 8. & $\begin{array}{l}\text { Do you have any other "handy hints" in } \\
\text { respect to raising a child with ASD that you } \\
\text { would like to pass on to other parents of } \\
\text { children with ASD? }\end{array}$ \\
\hline General Section \\
\hline 9. & $\begin{array}{l}\text { What three key messages about parenting a } \\
\text { child with ASD would you like everyone to } \\
\text { know? }\end{array}$ \\
\hline 10. & $\begin{array}{l}\text { What are your three top content priorities for } \\
\text { educational material to promote awareness, } \\
\text { acceptance and inclusion of children with } \\
\text { ASD? }\end{array}$ \\
\hline
\end{tabular}

Letters explaining the questionnaire and requesting that it be advertised in newsletters and on websites were sent to 300 schools and to a variety of ASD specific and general disability organisations. One hundred and thirty seven people completed the on-line questionnaire and it was analysed by the author to ascertain what parents considered priority content for the DVD.

\section{RESULTS 1}

\section{Key messages and experiences}

Data was analysed and the predominant messages parents wanted others to know were that:

- ASD is not an illness that can be cured;

- children with ASD think and act differently;

- people need to accept and accommodate these differences;

- include and treat children with ASD and their families with dignity and respect.

Parents described many different positive experiences that contributed to their children feeling valued and accepted. Generally these centred around children being accepted as friends by their peers, having accommodations made to enable inclusion in everyday and special activities and being shown acceptance and kindness. They stressed the importance of positive relationships

1 This article reports on information arising from the school, community and general sections of the questionnaire. Because of word limit restrictions, Maori specific data will be reported in a separate article. between their child and teacher, their child and peers and between home and school. A positive home-school partnership was seen as invaluable and professionals who took time to listen, support and affirm parents were greatly appreciated. As one parent noted:

Autism is a disorder which affects the child's and the family's whole life. If the child has autism the whole family is affected hugely, right from the early days. It is a lifelong disorder and so it does not go away or get cured! So, support for the child and family is critical, and ongoing.

\section{Messages to teachers and other educational professionals}

Parents noted that professionals ${ }^{2}$ should take time to get to know their students with ASD. By talking to parents and watching and listening to children's verbal and nonverbal communication, professionals can learn about their students' different behaviours, strengths, likes and dislikes. This information can then be used to create an ongoing profile and contribute to individualised teaching programmes and appropriate services. Parents also noted that, generally, professionals need better training to gain an understanding of ASD and to learn effective identification, teaching and behaviour management strategies.

Teaching strategies that parents reported as being particularly effective with their children were: whole class strategies; academic support; seating and breaks; using strengths and interests; advance warnings; home-school communication; playtime strategies; rewarding effort; safety strategies; and teaching modelling.

\section{Whole class strategies}

Whole class strategies included programmes, lessons, rules and routines applicable to all class members but especially helpful for children with ASD:

In my son's school they have values education which includes information about values such as being a friend, respect, resilience, and basic playing nicely guidelines. This has been great for him as everyone is learning the information he needs to understand - the social stuff. The teacher uses role play, comic strips in words or pictures and stories. We have discussed using learning stories as a class activity also.

These [routines] make the whole class run more efficiently and more organised.

\footnotetext{
2 Professionals refer to a range of occupations including teachers, teacher aides, psychologists, special education advisers, education support workers, speech language therapists and so forth.
} 


\section{Academic support}

This involved providing extra help and making accommodations where needed, for example, being able to use a keyboard if writing was difficult and providing reader/writers for tests where the intention was to measure the child's content knowledge rather than their test-taking ability. Many parents believed that the teacher needed to give more one-to-one assistance to their child and not to rely on the teacher-aide to provide this:

The teacher-aide is to help the school or main teacher. They are not the main teacher.

\section{Seating and breaks}

Often the strategies parents described were simple but effective:

A teacher let my child have one desk situated within a group, and another put to one side - so that when he was overloaded he could remove himself from other children in a noisy classroom. This is vital for any child who has problems with sensory integration.

Giving jobs like messages to the office where the staff are lovely to my boy! Using these messages as a movement break or to act as an emotional break just by sending a yellow card or his message so that the office knows he's having a break.

\section{Using strengths and interests}

Parents noted that teachers should identify student's strengths and interests and draw on these to capture their attention and facilitate learning. Children's strengths could also be used in other ways as the following examples demonstrate:

My child is really clever at dates - the teacher is always asking when things happened or whose birthday it is - showing off his talents.

My son (now an adult) has an excellent memory. The school identified his strength and used it to good advantage. If my son when aged 16-20 suffered any teasing by peers, these peers had to be challenged to a card game of memory with my son in front of his peers. Needless to say my son won every time. Consequently, my son suffered very little bullying and felt affirmed, valued, liked and accepted by school staff and peers. The school principal said to me that my son was very welcome in the school community and that his honesty was an asset to everyone.

Her teacher got children to write down one thing my daughter was good at and had this presented to her.

\section{Advance warnings}

These are important for children who find changes in routine or personnel particularly upsetting:

At my son's school the class for the following year got to meet their new class and teacher and did some activities in the new room. This was great for removing some of the anxiety for the following year.

If possible Jason is introduced to relievers before they are needed so he knows them before they turn up.

\section{Home-school communication - the diary}

Parents expressed a wish to be kept fully and honestly informed about their children's schoolwork, behaviour and socialisation. The home-school diary was frequently mentioned as an effective means of communication:

We have a set-up where our son carries a diary with him (preparing him for the future) and in this diary are messages from me, giving some insight to how he has been, what he has been doing (story writing prompts etc) and in return the school lets me know how his day has gone - the good and the bad and then I can give suggestions. Also in this diary is upcoming events so I can pre-warn him, this also includes known teacher absences. This reduces anxiety.

\section{Playtime strategies}

Playtime was reported as a particularly difficult time for children with ASD and parents emphasised the need for proactive strategies.

When Bernard is in a conflict situation he can't use words but becomes physical. He needs peer support set up in the playground so that other children can help to talk for him.

Understanding the child's personal needs e.g. don't touch the child from behind. Have a profile of the child drawn up with the teacher's/ parent's input plus a brief outline with photo for teachers on playground duty.

\section{Rewarding effort}

The power of positive reinforcement was acknowledged by parents. Some also noted that because of the challenges their children face, they had fewer opportunities to be rewarded for achievement than their classmates. Consequently, rewarding effort was mentioned as being particularly important:

My son really struggles to finish the crosscountry race every year and always comes in last for his age group. This year he received a Principal's Award for his "perseverance in the cross-country" - that made him feel really good, because his effort was rewarded. 
Everything my 8 year-old does in school is several times harder than it is for most of the others. He overcomes huge obstacles (sensory, fine- and gross-motor and social) to achieve what they achieve easily. Please note in his "keep in touch" daily book that he "tried hard today" so that he feels appreciated for his efforts even though it is way off the normal standard of children.

\section{Safety strategies}

Many parents expressed a concern about their children being bullied at school. As one mother reported:

Supervision tends to be minimal at breaks due to lack of funding. Bullying can be a huge issue and a person with a communication disorder isn't going to come home and say they're being bullied. Our son fell at school and broke his arm at 10 years old and it took five days to gradually get out the facts which were that he was chased by a group of boys with a praying mantis (he has an insect phobia).

Another parent confirmed this situation and added her suggestions to counteract bullying:

Other kids will tease and be hurtful as your kid is different. Please let parents know and be aware this will happen. Give them a place to go if feeling scared or left out. And also have a support person to talk to.

A further parental concern was of their children leaving school and wandering into unsafe situations. One parent whose son was "a runner" purposely chose a school that was situated away from busy streets to lessen the opportunity of him being involved in a road accident. Some schools require children with ASD to wear brightly coloured, high visibility vests to enable teachers on duty to easily identify them. One parent commented on this practice. She was not happy that the vest singled her child out as being different from his peers but, because his safety was paramount, she accepted this situation. (The exact response was given by another parent in a study by Bevan-Brown et al., 2010.)

\section{Teacher modelling}

Parents believed that all adults who work with and care for children with ASD have important roles to play in modelling appropriate behaviours. As one parent explained:

Be aware that your student with ASD needs high status in the classroom. If the teachers do not value the ASD student, the students will not either...Teachers model respect and allowances for differences.

\section{Messages to peers}

As mentioned previously, friendships were an area of major concern for parents. They desperately wanted their children to be accepted by peers, to have friends home to play, to be invited to birthday parties and so forth. However, they were well aware that their child's behaviour often frightened potential friends away rather than attracting them. They believed that if classmates and their families had a greater understanding of ASD in general and their child in particular, there would be a greater likelihood of friendships developing:

He has a 'different not deficient' way of thinking and acting.

If you're different - doesn't mean you don't deserve to have friends. Everyone needs friends. If he pinches/pulls hair he doesn't understand that he is hurting people and doesn't realise that he shouldn't do it.

She can be a very good, loyal friend to anyone who can look past the quirkiness (and that the quirkiness will be much less when she feels welcome and wanted).

Don't tell him to do dangerous, rude things because he will as he thinks that you said it and you are his friend.

Parents believed that teachers and teacher-aides should spread these messages and also encourage and nurture friendships between children with ASD and their peers.

Three mothers reported visiting their child's class at the beginning of each year to tell new classmates about their child and about ASD. In each instance it was considered a very worthwhile exercise for everyone concerned. ${ }^{3} 4$

\section{Messages to community members and other parents}

Parents reported a range of challenges they faced in community settings. As many children with ASD find new situations difficult to handle and are sensitive to being touched, visits to the dentist, doctor and hairdresser can be particularly stressful. Parents emphasised that careful "preparatory work" is essential. They suggested strategies such as visiting or phoning the service provider beforehand to explain their child's particular behaviours. ${ }^{5}$ Asking for the first appointment of the day or afternoon was also recommended to avoid

\footnotetext{
3 For a good example of this read Wastney, B., Te Kooro-Baker, G., \& McPeak, C. (2007). Parental suggestions for facilitating acceptance and understanding of Autism. Kairaranga, 2007, 8(2), 15-20.

4 The "In my shoes" DVD has sections that can be used to explain ASD to both primary and secondary school students.

5 Now the "In my shoes" DVD is available it can be shared with the service provider prior to the child's visit.
} 
long waits in hot, crowded waiting rooms. Other preparatory strategies included role-playing the situation, looking at photos of the doctor, dentist or hairdresser and their premises, and writing social stories about the upcoming event.

Palmerston North Hospital provides a good model for others to follow. A parent panel is regularly invited to speak to groups of hospital staff to explain their children's behaviours and make suggestions about how they can be accommodated. Over the years some excellent practices and relationships have evolved. For example, one mother explained that her son needs to be given a general anaesthetic for dental work. On such occasions she is invited to bring along her hairclippers and give her son a haircut while he is still anaesthetised.

Another activity that parents reported being particularly stressful is taking their children shopping. As one mother commented:

Don't judge, but offer to help. Often you have a child packing a tantrum in a shop because they really want something and you have said no. Even though the child has been adequately prepared for what you are going to buy etc. mine currently gets angry and runs out of the shop telling me that I am every obscenity under the sun (behaviour that comes from Spongebob ... arghhh!!) Don't ridicule me as I try to ignore this behaviour or tell me all he needs is a good smack etc, as I'm trying to keep it all together and not burst into tears. Offer to help or keep your thoughts to yourself.

It was suggested that, if possible, parents should choose less busy shopping times and go to the same cashier so that the child and cashier get to know each other. Other recommended strategies were the promise of a reward for appropriate behaviour, and toys and books to divert children's attention when they become anxious. One mother explained how her son has "a bum bag that contains a selection of little cars and figurines that are the currect favourite. When I notice him getting worked up I tell him to unzip his bag and that usually works really well."

Safety in the community was a further parental concern, especially as many children with ASD are inclined to wander away from home. Government funding is available to fence properties but this is not always a viable option for parents. One mother explained how she had developed a profile of her son which included his photo and her contact details. This was distributed to selected neighbours who were asked to contact her if they ever noticed her son wandering alone in the neighbourhood.

\section{Some final messages}

While the interview questions were focused on positive experiences and successful strategies, unfortunately parents also reported a considerable number of negative attitudes and experiences they have had to contend with. The final messages reflect some of these frustrations:

It's not contagious!!!! Parents need support, they need a break, they need not to have to battle agencies for funding etc.

Not having a 'social' sense is as much of a deficit as not having one of your other five senses.

"If you are low functioning they tend to underestimate your strengths and if you are high functioning they underestimate your weaknesses." Can't remember whose quote this is but I thought it summed it up well... Never underestimate their ability no matter what anyone else says.

See them for who they are rather than how you think they should be.

Teachers need to understand that they cannot "cure" ... they wouldn't think that a blind child would get their sight after being in their class a few weeks! Instead they have a wonderful opportunity to enhance the child's skills.

When liaising with parents just remember if it's hard for you to manage at school, imagine how challenging it is $24 / 7$ !

\section{DISCUSSION}

Teachers and other professionals readily accept that parents know their children best but often they are not as willing to admit that many parents are also very knowedgeable about their child's particular disability and associated teaching approaches and strategies. As a result, parents' opinions and suggestions are sometimes not given the credence they deserve and may even be discounted altogether. Having a child with a disability is a powerful motivator to find out as much as possible about the child's condition and about ways they can be helped. Messages from the 137 parents who participated in this on-line questionnaire are well-aligned with ASD research findings. In fact, their key messages and experiences reported above are all supported in The New Zealand Autism Spectrum Disorder Guideline (Ministries of Health and Education, 2008) which is recognised as New Zealand's most authoritative, comprehensive publication on ASD.

Parental feedback did not focus on theoretical approaches, models or programmes for children with ASD. Rather they reported on particular 
strategies that had proved effective with their children and on broad underpinning philosophies and practices. Most of their suggestions are simply good teaching practice regardless of whether or not the child has ASD. While being good general teaching practices, these strategies also have particular relevance to children with ASD. This is supported in the ASD Guideline where, for example, there are recommendations and good practice points specifically focused on using strengths (3.2.4.2, 5.2.3); incorporating interests (3.1.11, 3.2.4.3, 5.2.3); providing academic supports to enhance learning (3.2.4.5); providing breaks and withdrawal to avert overload situations (3.3.3, 4.6.4); informing peers and supporting, encouraging and fostering social relationships (3.4.2, 5.2.8); preparing children for transitions (3.4.5); proactive crisis support planning (4.7.2) and the importance of safety strategies (5.3.3, 5.3.10, 5.3.11). Furthermore, recommendation 3.1.10 states that "Families should be part of the team involved in the development of priority goals and intervention plans" (p. 87).

The predominant concerns mentioned by parents in this study i.e. wanting their children to be happy, have friends and be safe in the school and community are concerns typical of all parents. However, because of the nature of ASD, they have added urgency for these parents. This contention is supported by research that shows children with ASD:

- are less likely to have friends (Carter, 2009; Myles \& Simpson, 1998);

- are more likely to be bullied at school (Little, 2002; Montes \& Halterman, 2007);

- are at high risk of internalising problems (Ghazuiddin, Weidmer-Mikhail \& Ghazuiddin, 1998);

- have above-average mortality rates compared to their peers especially concerning death from 'unnatural causes', such as suicide and accidents (Mouridsen, Bronnum-Hansen, Rich \& Isager, 2005);

- have a higher prevalence of anxiety and mood problems than children without ASD (Kim, Szatmari, Bryson, Streiner \& Wilson, 2000);

- have comparatively high rates of depression (Ghazuiddin, Ghazuiddin \& Greden, 2002);

- as adolescents and adults, are disproportinately represented amongst crime victims (Petersilia, 2001).

In conclusion, research shows that the concerns expressed by parents in this study are definitely warranted and the strategies suggested for helping their children are strongly evidence-based.

Everyone will benefit from heeding these parents' messages - it is a win-win situation.

\section{REFERENCES}

Bevan-Brown, J. Bourke, R., Butler, P., Carroll-Lind, J., Kearney, A., \& Mentis, M. (2010). Evaluation of the 'tips for autism' professional learning and development programme. Education report, year three. Palmerston North: Massey University College of Education.

Carter, S. (2009). Bullying of students with asperger syndrome. Issues in Comprehensive Pediatric Nursing, 32, 145-154.

Ghazuiddin, M., Ghazuiddin, N., \& Greden, J. (2002). Depression in persons with autism: Implications for research and clinical care. Journal of Autism and Developmental Disorders, 32(4), 299-306.

Ghazuiddin, M., Weidmer-Mikhail W.K., \& Ghazuiddin, N. (1998). Comorbidity of asperger syndrome: A preliminary report. Journal of Intellectual Disability Research, 42, 45-48.

Kim, J., Szatmari, P., Bryson, S. E., Streiner, D. L., \& Wilson, F. J. (2000). The prevalence of anxiety and mood problems among children with autism and asperger syndrome. Autism, 4(2), 117-132.

Little, L. (2002). Middle-class mothers' perceptions of peer and sibling victimization among children with asperger's syndrome and non-verbal learning disorders. Issues in Comprehensive Pediatric Nursing, 24, 43-57.

Ministries of Health and Education (2008). New Zealand Autism Spectrum Disorder Guideline. Wellington, New Zealand: Ministry of Health.

Montes, G.,\& Halterman, J. (2007). Bullying among children with autism and the influence of comorbidity with ADHD: A Population-Based Study. Ambulatory Pediatrics, 7(3),253-257.

Mouridsen, S., Bronnum-Hansen, H., Rich B., \& Isager, T. (2005). Mortality and causes of death in Autism Spectrum Disorders. An update. Autism, $12(4), 403-414$.

Myles B. \& Simpson R.L. (1998). Asperger syndrome: A guide for educators and parents. Austin, TX: Pro-Ed.

Petersilia, J.R. (2001). Crime victims with developmental disabilities. A review essay. Criminal Justice and Behaviour, 28(6), 655-694.

Wastney, B., Te Kooro-Baker, G., \& McPeak, C. (2007). Parental suggestions for facilitating acceptance and understanding of Autism. Kairaranga, 8(2), 15-20. 


\section{AUTHOR'S PROFILE}

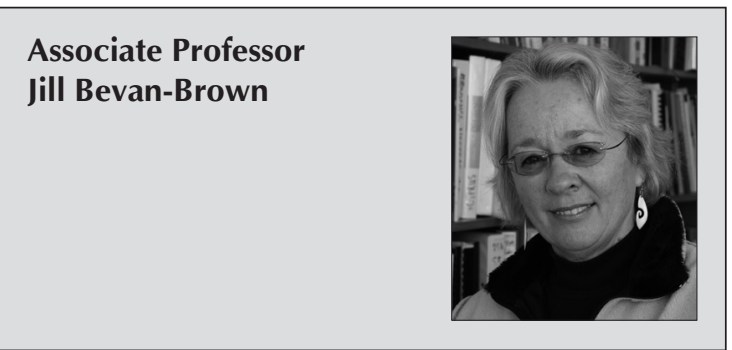

Associate Professor Jill Bevan-Brown is responsible for the B.Ed (Special Education) and is Director of the Inclusive Education Research Centre at Massey University. Being of Māori ancestry she has a particular interest in culturally appropriate provisions for Māori learners with special needs including gifted Māori children.

EMAIL

j.m.bevan-brown@massey.ac.nz 